\title{
BOXFISHES (TELEOSTEI: OSTRACIIDAE) AS A MODEL SYSTEM FOR FISHES SWIMMING WITH MANY FINS: KINEMATICS
}

\author{
J. R. HOVE*,1, L. M. O'BRYAN ${ }^{2}$, M. S. GORDON², P. W. WEBB ${ }^{3}$ AND D. WEIHS ${ }^{4}$ \\ ${ }^{1}$ Option of Bioengineering, California Institute of Technology, Pasadena, CA 91125, USA, \\ ${ }^{2}$ Department of Organismal Biology, Ecology and Evolution, University of California, Los Angeles, CA 90095, USA, \\ ${ }^{3}$ School of Natural Resources and Department of Biology, University of Michigan, Ann Arbor, MI 48109, USA and \\ ${ }^{4}$ Department of Aerospace Engineering, Technion, Haifa 32000, Israel \\ *e-mail: jhove@caltech.edu
}

Accepted 30 January; published on WWW 28 March 2001

\begin{abstract}
Summary
Swimming movements in boxfishes were much more complex and varied than classical descriptions indicated. At low to moderate rectilinear swimming speeds $\left(<5 T L \mathrm{~s}^{-1}\right.$, where $T L$ is total body length), they were entirely median- and paired-fin swimmers, apparently using their caudal fins for steering. The pectoral and median paired fins generate both the thrust needed for forward motion and the continuously varied, interacting forces required for the maintenance of rectilinearity. It was only at higher swimming speeds (above $5 T L \mathrm{~s}^{-1}$ ), when burst-and-coast swimming was used, that they became primarily body and caudal-fin swimmers. Despite their unwieldy appearance and often asynchronous fin beats,

was characterized by varying fin-beat frequencies and amplitudes as well as synchrony in pectoral fin motions. The remainder of the second gait $\left(3-5 T L \mathrm{~s}^{-1}\right)$ was characterized by constant fin-beat amplitudes, varying finbeat frequencies and increasing pectoral fin-beat asynchrony. The third gait $\left(>5 T L \mathrm{~s}^{-1}\right)$ was characterized by the use of a caudal burst-and-coast variant. Adduction was always faster than abduction in the pectoral fins. There were no measurable refractory periods between successive phases of the fin movement cycles. Dorsal and anal fin movements were synchronized at speeds greater than $2.5 T L \mathrm{~s}^{-1}$, but were often out of phase with pectoral fin movements.
\end{abstract} boxfish swam in a stable manner. Swimming boxfish used three gaits. Fin-beat asymmetry and a relatively nonlinear swimming trajectory characterized the first gait $\left(0-1 T L \mathrm{~s}^{-1}\right)$. The beginning of the second gait $\left(1-3 T L \mathrm{~s}^{-1}\right)$

Key words: fish, swimming, kinematics, ostraciiform mode, gait, boxfish, Ostracion meleagris camurum.

\section{Introduction}

Destabilizing recoil forces generated by the yaw and sideslip inherent in undulatory body and caudal-fin (BCF) modes of rectilinear fish swimming are thought to produce significantly more drag than is expected in fishes swimming with rigid bodies (Lighthill, 1971; Webb, 1975). Empirical studies on BCF swimmers support the assertion that body-flexing systems create recoil forces that displace them from their desired direction of travel (Videler and Wardle, 1978; Videler and Hess, 1984; Webb, 1988a). Gordon et al. (Gordon et al., 1996) observed that pufferfish (Arothron hispidus and A. meleagris) using the rigid-bodied median- and paired-fin (MPF) tetraodontiform mode of locomotion showed no detectable yaw or sideslip over a full range of swimming speeds. They suggested that the steady swimming trajectories of the pufferfish might be due to the use of multiple peripherally located propulsors operating on their rigid bodies as opposed to thrust-generating systems utilizing body flexure.

Closely related to pufferfish are another group of fishes that swim with rigid bodies, the boxfishes (family Ostraciidae).
Examination of the boxfish bauplan (their bodies are largely enclosed in rigid, bony carapaces) suggests that these animals also use multiple, peripheral propulsors to swim at lower speeds. Interestingly, boxfishes have been the benchmark for classical descriptions of 'ostraciiform' locomotion as a BCF mode with minimal body curvature in which a sculling caudal fin is the primary propulsor (Breder, 1926; Blake, 1977; Blake, 1981). Preliminary observations, both in the laboratory and in the field, suggested that boxfishes normally do not swim in this classical mode: they use their median and paired fins as the major propulsors for most of their speed range. Thus, boxfishes should be considered as MPF, not BCF, swimmers. The present study documents this difference in swimming mode.

The Hawaiian spotted boxfish Ostracion meleagris is a diurnally active inhabitant of tropical reefs and lagoons from east Africa to the eastern Pacific Ocean (Randall, 1972). Like other ostraciids, the species has the anterior three-quarters of its body encased within a bony carapace. The carapace in this species is near trapezoidal in cross section with a convex 


\section{J. R. HOVE AND OTHERS}

dorsum, flatter ventrum and concave 'flutes' along the lateral surfaces (see Fig. 1A-C). The carapace prevents body flexure forward of the caudal peduncle.

Here, we describe quantitatively the kinematics of locomotion in $O$. m. camurum (the Hawaiian subspecies) using high-speed video- and computer-based image analyses. We examine both the motions of individual fins and how those fins work together in coordinated ways over a range of induced swimming speeds. We also quantify the deviations from the mean paths of boxfish swimming trajectories (recoil movements) to compare these measures statistically with similar data from other fish species utilizing varying degrees of body undulation. The results of these comparisons will test the prediction that rigid-bodied, multi-propulsor swimmers exhibit less recoil than their BCF counterparts.

\section{Materials and methods}

Boxfish Ostracion meleagris were collected by hand net in 1-10 m of water from Kahe Point and Makapuu Point, Oahu, Hawaii. Fish were held individually in flow-through aquaria under a light regime of $12 \mathrm{~h}: 12 \mathrm{~h} \mathrm{~L}: \mathrm{D}$. Water temperature and salinity were $27 \pm 1^{\circ} \mathrm{C}$ and $32 \pm 2 \%$ respectively. Boxfish were fed a gel diet once per day consisting of smelt, squid, algae and vitamins. Observations were made on ten individuals $(10.4-15.0 \mathrm{~cm}$ total length, $T L)$. There are no recorded dimorphisms that are believed to affect swimming performance (Randall, 1972), so results for males and females were pooled. All boxfish used were released within 14 days of their original capture. A voucher specimen of Ostracion meleagris camurum Jenkins, 1901 that had been obtained from a Hawaiian commercial source for previous studies has been deposited in the UCLA Ichthyological Research Collection (UCLA W83-21).

\section{Physical characteristics of fish}

Measurements of body and fin characteristics were made at UCLA on six fish (10.4-14.0 cm TL) obtained from Hawaiian dealers (Table 1). Fish were killed with an overdose of 3- aminobenzoic acid ethyl ester (MS-222) and blotted dry. Body circumferences were measured along each fish's length at $1 \mathrm{~cm}$ intervals starting from the tip of the snout, using thread. The total wetted surface area of the body, $A_{\mathrm{b}}$, was estimated by summing the length-wise strips (mean circumference $\times$ interval width) for each fish. The shapes of fully expanded pectoral, anal, dorsal and caudal fins were traced onto tared paper, and the surface areas $\left(A_{\text {fin }}\right)$ were determined from the masses of the fin silhouettes. Aspect ratios of the fins $\left(A R_{\text {fin }}\right)$ were determined from the ratio (span) $2 /$ area, span being measured near the leading edge at the second fin ray. These data were all regressed on total length (TL) to estimate values for fish used in swimming experiments.

Whole-body densities were determined by weighing the fish to within $10^{-4} \mathrm{~g}$ in air and in sea water (Arnold and Weihs, 1978). Fish were attached to a Mettler balance by a thread and weighed in air after blotting. Weights in water were similarly determined after removing adhering bubbles with a paintbrush. Measurements in both air and sea water were repeated three times; measurements were repeatable to $0.01 \%$.

The position of the center of mass in the $x z$ plane was estimated by suspending the fish from three different locations on the body against plumb lines. The point of intersection of these lines was considered to be the center of mass. The center of buoyancy was calculated as the center of mass of the fish when completely submerged in water (Weihs, 1993). Each plumb line position for submerged fish was drawn on a boxfish diagram using landmark positions (e.g. body spots) to describe the lines. The lines were then transcribed back onto the fish and the points of intersection recorded. The $y$ dimensions of both the center of mass and center of buoyancy were estimated by assuming that both were located on the body midline.

\section{Apparatus}

Fish were videotaped over their full MPF range of swimming speeds in a 2001, closed-circuit, Brett-type water tunnel (Gordon et al., 1996). The inner dimensions of the Plexiglas working section were $73 \mathrm{~cm} \times 23 \mathrm{~cm} \times 23 \mathrm{~cm}$ (length $\times$ width $\times$ height). Fish swam in an observation section $50 \mathrm{~cm}$ in

Table 1. Body and fin measurements for six Hawaiian boxfish Ostracion meleagris camurum

\begin{tabular}{|c|c|c|c|c|c|c|c|c|c|c|c|c|}
\hline \multirow{3}{*}{$\begin{array}{l}\text { Fish } \\
\text { number }\end{array}$} & \multirow{3}{*}{$\begin{array}{c}T L \\
(\mathrm{~cm})\end{array}$} & \multirow{3}{*}{$\begin{array}{c}\text { Mass } \\
(\mathrm{g})\end{array}$} & \multirow{3}{*}{$\begin{array}{l}\text { Density } \\
\left(\mathrm{g} \mathrm{cm}^{-3}\right)\end{array}$} & \multicolumn{4}{|c|}{$A_{\text {fin }}$} & \multirow{3}{*}{$\begin{array}{c}A_{\mathrm{b}} \\
\left(\mathrm{cm}^{2}\right)\end{array}$} & \multirow{3}{*}{$\begin{array}{c}A_{\mathrm{Tot}} \\
\left(\mathrm{cm}^{2}\right)\end{array}$} & \multirow{2}{*}{\multicolumn{3}{|c|}{$A R_{\text {fin }}$}} \\
\hline & & & & \multirow{2}{*}{$\begin{array}{c}A_{\mathrm{p}} \\
\left(\mathrm{cm}^{2}\right)\end{array}$} & \multirow{2}{*}{$\begin{array}{c}A_{\mathrm{d}} \\
\left(\mathrm{cm}^{2}\right)\end{array}$} & \multirow{2}{*}{$\begin{array}{c}A_{\mathrm{a}} \\
\left(\mathrm{cm}^{2}\right)\end{array}$} & \multirow{2}{*}{$\begin{array}{c}A_{\mathrm{c}} \\
\left(\mathrm{cm}^{2}\right)\end{array}$} & & & & & \\
\hline & & & & & & & & & & $A R_{\mathrm{p}}$ & $A R_{\mathrm{d}}$ & $A R_{\mathrm{a}}$ \\
\hline 2 & 14.0 & 77.2 & 1.0374 & 3.29 & 3.57 & 3.30 & 9.7 & 102.4 & 125.6 & 2.2 & 1.5 & 1.8 \\
\hline 3 & 10.6 & 30.5 & 1.0361 & 1.92 & 2.00 & 1.72 & 5.5 & 59.8 & 72.9 & 1.6 & 1.6 & 1.6 \\
\hline 4 & 13.6 & 71.1 & 1.0330 & 2.10 & 2.85 & 3.08 & 8.7 & 95.8 & 114.6 & 2.1 & 1.5 & 1.8 \\
\hline Mean & 12.1 & 50.7 & 1.0355 & 2.49 & 2.45 & 2.40 & 7.1 & 76.7 & 93.8 & 1.9 & 1.5 & 1.7 \\
\hline S.E.M. & 0.6 & 8.1 & 0.0009 & 0.20 & 0.32 & 0.35 & 0.8 & 9.0 & 11.1 & 0.1 & 0.02 & 0.04 \\
\hline
\end{tabular}

$T L$, total body length (cm); $A_{\text {fin }}\left(A_{\mathrm{p}}\right.$, pectoral; $A_{\mathrm{d}}$, dorsal; $A_{\mathrm{a}}$, anal; $A_{\mathrm{c}}$, caudal), fin surface area; $A_{\mathrm{b}}$, body surface area; $A_{\text {Tot }}$, total fish surface area; $A R_{\text {fin }}$, fin aspect ratio $=S_{\text {fin }}{ }^{2} / A_{\text {fin }}$, where $S_{\text {fin }}$ is fin $\operatorname{span}(\mathrm{cm})$. 
length bounded at its up- and downstream ends with smooth plastic collimators (Plascor Inc.; $6 \mathrm{~mm}$ diameter circular grid).

Flows of $5-91 \mathrm{~cm} \mathrm{~s}^{-1}( \pm 6 \%)$ were generated by a variablespeed $746 \mathrm{~W}(1 \mathrm{hp})$ continuous-duty Minarik electric motor attached to a $19 \mathrm{~cm}$ diameter three-bladed propeller and controlled by a Minarik XL Series Motor Master speed control with an integrated digital tachometer.

Flow characteristics were evaluated using a variety of methods. The absence of large-scale turbulence was verified using injected dye streams and short threads attached to the collimator just upstream of the observation section. Flow patterns were visualized over a wide range of flume speeds using high-speed videotape ( 250 frames s$^{-1}$ ) of neutrally buoyant $3.2 \mathrm{~mm}$ diameter Teflon spheres (Polysciences Inc.) viewed against a $5 \mathrm{~cm}$ grid. The cross-sectional flow profiles were found to be uniformly rectilinear.

\section{Experimental procedures}

A single boxfish was transferred from a holding tank to the observation section of the flume at a current speed of approximately $0.5 T L \mathrm{~s}^{-1}$. Fish were acclimated in the flume for a minimum of $1 \mathrm{~h}$ before videotaping commenced.

At the end of this period, swimming speed was increased by $0.5 T_{L ~ ~^{-1}}$ every $10-15$ min until the fish was pinned against the downstream screen. The fish was then removed, lightly anesthetized with 2-phenoxyethanol (1:7000), and its mass (to within $0.01 \mathrm{~g}$ ) and total length (to within $0.1 \mathrm{~cm}$ ) were measured.

Swimming movements were simultaneously recorded in lateral and in ventral or dorsal views via a $45^{\circ}$ mirror, using two synchronized Redlake HR500 digital video cameras triggered externally and recording at 120 frames $^{-1}(1 / 240 \mathrm{~s}$ shutter speed). Three video segments were recorded at each speed. The observation section was illuminated with two $250 \mathrm{~W}$ tungsten lamps. The top or bottom and back of the observation section were lined with Scotchlite, marked with $5 \mathrm{~cm}$ grids, to provide both fish position and clear, high-contrast images.

\section{Videotape analysis}

Videotaped sequences were grabbed frame-by-frame and digitized with a Motus v.3.0, Peak Performance Technologies Inc. video-analysis system and analyzed to measure body positions and the kinematics of the pectoral, dorsal, anal and caudal fins. Only video segments in which speed varied by a no more than $10 \%$ and fish remained at least $2.5 \mathrm{~cm}$ away from walls were analyzed. Measurements of nine landmarks in lateral view and six landmarks in ventral view were made for every fourth frame during 5-7 fin-beat cycles. The landmarks were (lateral views) the lower jaw tip, the anal, pectoral and dorsal fin origins, the upper and lower trailing edges of the caudal fin, and the distal tip of the leading edge on the pectoral, dorsal and anal fins; and (ventral view) the lower jaw tip, the caudal fin tip, the anal fin origin and the distal tip of the leading edge on the right pectoral, left pectoral and anal fins (Fig. 1A,C). If a landmark was not visible in either camera view, the coordinates were interpolated using Fourier approximations (Baroni, 1994). More than 27000 frames were digitized for this study.

Position within the working section varied among individual fish, preventing a priori calibration of the specific three-

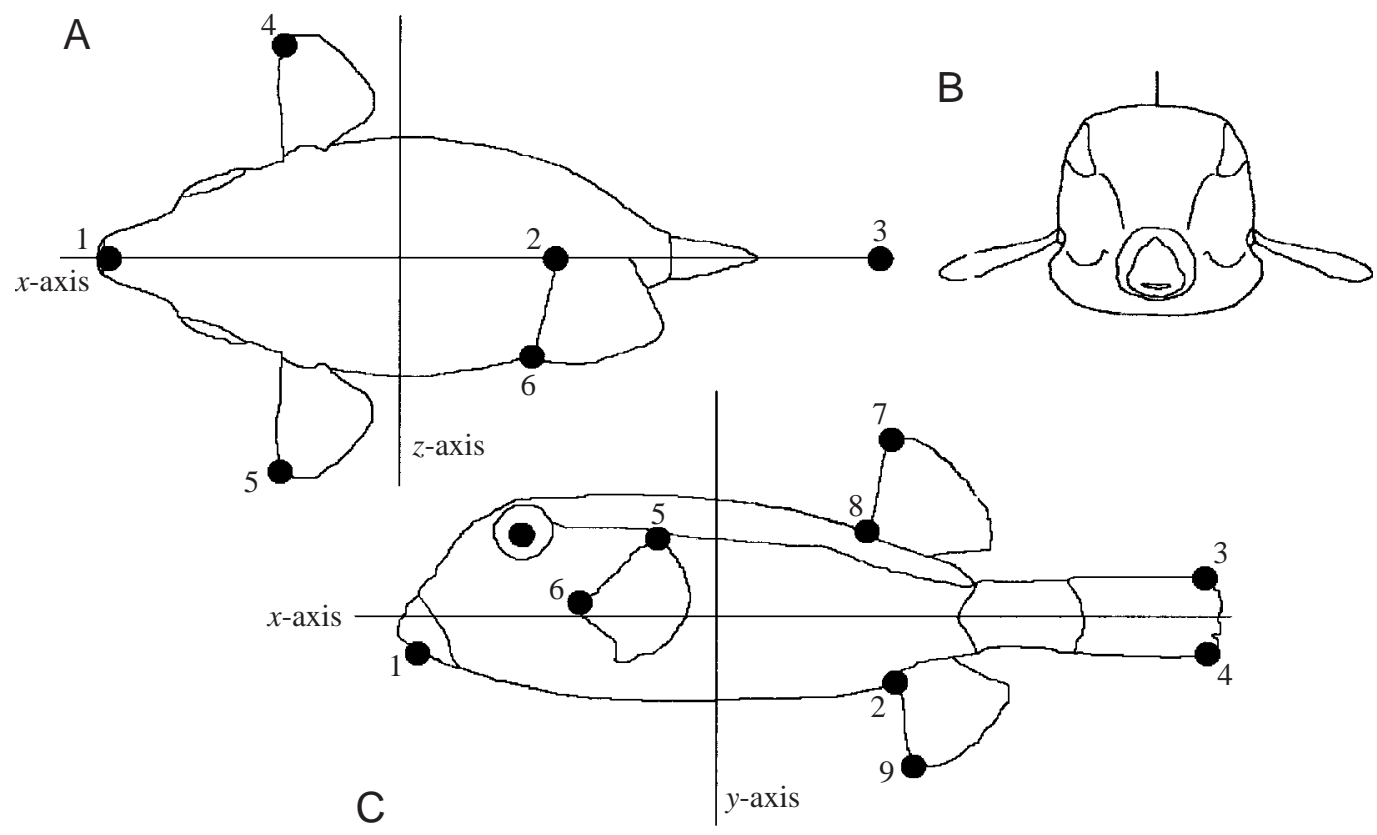

Fig. 1. Diagrams illustrating the body shape, landmarks and dimensional axes of the Hawaiian boxfish Ostracion meleagris camurum from three perspectives. (A) Ventral view markers: 1, lower jaw; 2, anal fin insertion; 3, caudal fin tip; 4, right pectoral fin (distal tip of leading edge); 5, left pectoral fin (distal tip of leading edge); 6, anal fin (distal tip of leading edge). (B) frontal view. (C) Lateral view markers: 1 , lower jaw; 2, anal fin insertion; 3, caudal fin (upper trailing edge); 4, caudal fin (lower trailing edge); 5, pectoral fin (distal tip of leading edge); 6, pectoral fin insertion; 7, dorsal fin (distal tip of leading edge); 8, dorsal fin insertion; 9, anal fin (distal tip of leading edge). 


\section{J. R. HOVE AND OTHERS}

Fig. 2. Schematic diagram of the dorsal/anal fin (A) and pectoral fin (B) positions with associated reference values (in degrees), as described in the text.
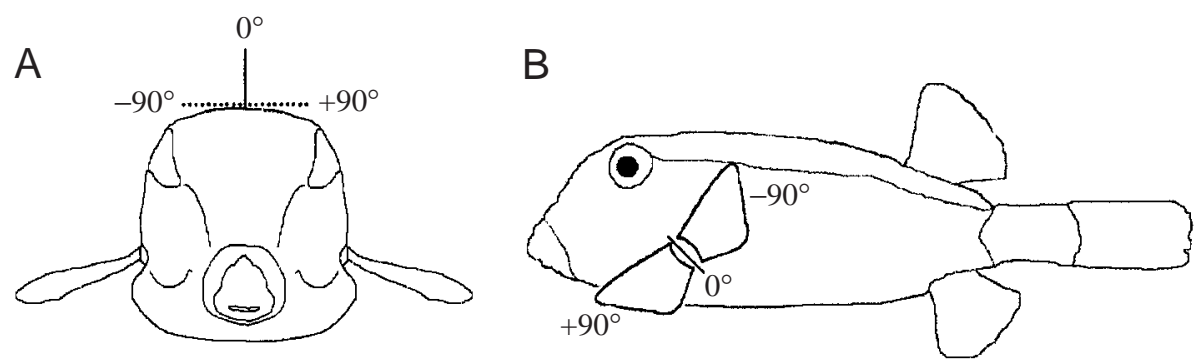

dimensional space in which the fish swam. Videotaped sequences (both views) of a 30-point calibration model were digitized immediately after each experiment. The motionanalysis software used these calibration data as a spatial baseline for subsequent digitization of fish landmarks.

\section{Propulsor kinematics}

Marking boxfish fins for ease in making kinematic measurements was unsuccessful. A number of techniques were tried, including the application of small aluminum clips (Walker and Westneat, 1997), chalk dust/cyanoacrylate spots (Drucker and Jensen, 1997) and tattooing (Haines and Modde, 1996), but none yielded consistently satisfactory results on the very fragile median and paired fins. As a result, the videotaped coordinates of the fin tips were digitized manually and used to quantify fin-beat kinematics. Median fin-beat cycles were defined as starting from and returning to the maximum (left or right) lateral excursion. Pectoral fin-beat cycles started with the fins pressed against the body (maximally adducted), moving away (abducting) from the body to some maximum point of excursion and returning (adducting) to the original position. Fin-beat frequencies were calculated at each swimming speed for all fins. The durations of abduction, adduction and any refractory period were also determined for these fins. Fin-beat amplitudes were calculated as the linear distances between maximum displacements of the fin tips during a fin-beat cycle divided by fin span to standardize for differences in fish size. In theory, the maximum relative amplitude should not exceed 2.

\section{Propulsor coordination}

Standard 'phase difference' techniques cannot be used to describe coordination between the movements of boxfish fins because there is temporal asymmetry between the two halves of pectoral fin beats. To describe propulsor coordination, we examined the individual Cartesian coordinates of fin tip positions from a single fin beat for each propulsor at several different swimming speeds. The duration of a single fin-beat cycle, at a given speed, was divided into $360^{\circ}$ and plotted versus time. We define $0^{\circ}$ as the point of maximum velocity for each fin type (i.e. vertical along the ventral midline for the anal fins, and midway between maximum abduction and adduction for the pectoral fins). Maximal dorsal/anal excursions to the left and right are assigned to $+90^{\circ}$ and $-90^{\circ}$, respectively, as are full pectoral abduction and adduction (Fig. 2). Plots of fin position (degrees) over the time between digitized points within a fin beat $(\tau)$ allow the temporal differences $(\mathrm{d} t)$ between 'zero-crossings' of the fin trajectories moving in the same direction to be calculated. The quotient $\mathrm{d} t / \tau$ can then be examined over a range of relative swimming speeds to estimate the phase relationships between the propulsors moving in non-sinusoidal trajectories.

\section{Recoil measurements}

There are six possible recoil motions for a rigid body resulting from propulsor movements, three of them translational and three rotational (Fig. 3A,B). Translational recoil is deviation in a plane containing the center of mass. Rotational recoil is rotatory movements about an axis that passes through the center of mass. Therefore, recoil motions should, in principle, be measured at the center of mass. This cannot be marked in a fish. Instead, the location was determined by triangulation from the digitized coordinates in ventral views for the lower jaw tip, the base of the leading ray
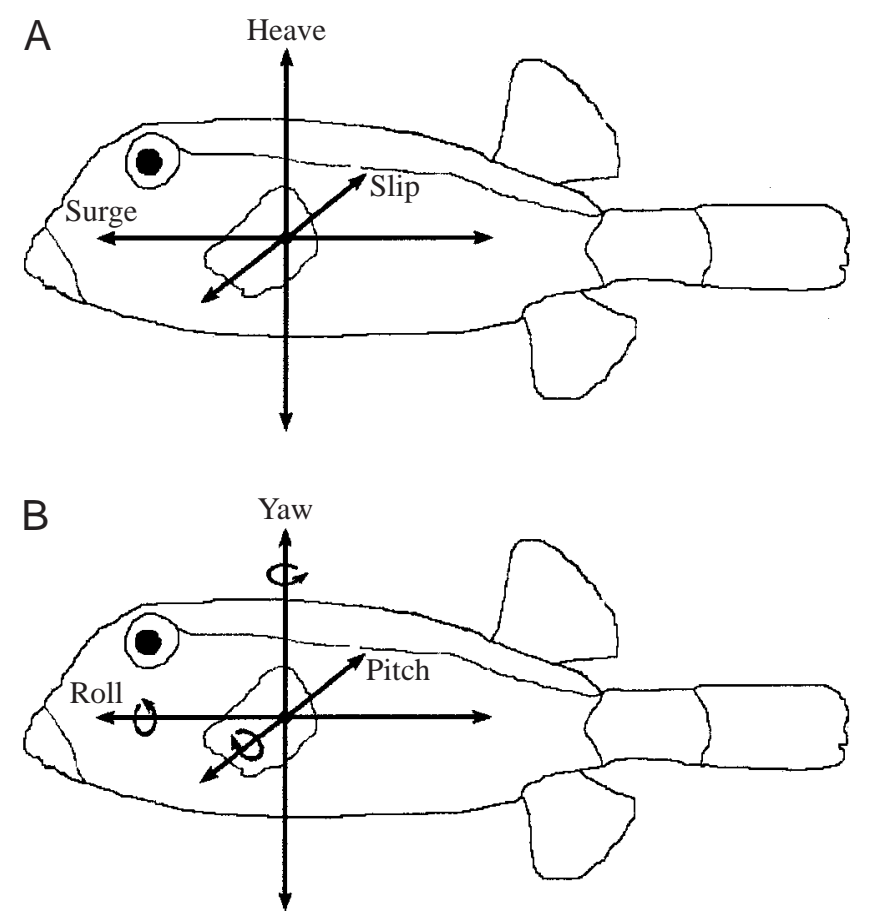

Fig. 3. Dimensional diagram of recoil geometries for Ostracion meleagris camurum. (A) Translational recoil motions about the center of mass. (B) Rotational recoil motions; curved arrows represent rotation about an axis. 
of the left pectoral fin and the anus. Yaw and pitch were estimated by the angles subtended by lines connecting the interpolated (virtual) center of mass and the snout tip in ventral and lateral views respectively. Sideslip and roll were estimated together by the $y$-dimensional (side-to-side) movements of the anus (ventral view). Motions of the virtual center of mass in the $z$ and $x$ dimensions approximated heave (with roll) and surge respectively.

\section{Statistical analyses}

Sample means were compared using Student's $t$-tests or onefactor analysis of variance (ANOVA), as appropriate. Linear regressions were used to describe the relationships between kinematic variables and time, while an analysis of covariance (ANCOVA) was employed to determine homogeneity between the slopes of regressions. Results were considered significant if $P<0.05$. Analyses were performed using Statistica v5.0 (Statsoft). Values are presented as means \pm 1 S.E.M.

\section{Results \\ Physical characteristics}

The mean mass of the boxfish was $50.7 \pm 8.1 \mathrm{~g}(N=6)$ and mean density was $1.0355 \pm 0.0009 \mathrm{~g} \mathrm{~cm}^{-3}$. The mean body density of $O . m$. camurum is well within the recorded range for marine fishes but is surprisingly low considering that a boxfish carapace comprises approximately $22 \%$ of the total body mass (based on our dissection data; Table 2).

The center of mass was located $31 \pm 3 \% T L$ posterior of the snout tip ( $x$ dimension) and $5.8 \pm 0.3 \% T L$ dorsal of the pectoral fin base origin ( $y$ dimension), as in other species (Domenici and Blake, 1991; Webb and Weihs, 1994). The mean center of buoyancy was located $24 \pm 3 \% T L$ posterior to the snout tip and $5.3 \pm 0.6 \% T L$ dorsal of the origin of the pectoral fin base.

The projected surface areas of the dorsal and anal fins were not significantly different, having areas of $2.45 \pm 0.32 \mathrm{~cm}^{2}$ and $2.40 \pm 0.35 \mathrm{~cm}^{2}$ respectively. The left and right pectoral fins were statistically equal in area (right pectoral, $A_{\mathrm{rp}}$, $2.67 \pm 0.35 \mathrm{~cm}^{2}$; left pectoral, $A_{\mathrm{lp}}, 2.31 \pm 0.31 \mathrm{~cm}^{2}$ ), averaging $2.49 \pm 0.20 \mathrm{~cm}^{2}$, statistically equal to the area of the dorsal and anal fins. The mean area of the fully expanded caudal fin $\left(A_{\mathrm{c}}\right)$ was $7.1 \pm 0.8 \mathrm{~cm}^{2}$. Mean body surface area $\left(A_{\mathrm{b}}\right)$ and total fish surface area $\left(A_{\mathrm{Tot}}=A_{\mathrm{b}}+A_{\mathrm{fin}}\right)$ were $76.7 \pm 9.0$ and $93.8 \pm 11.1 \mathrm{~cm}^{2}$ respectively. Aspect ratios $\left(\operatorname{span}^{2} / A_{\text {fin }}\right)$ were similar for all fins, varying between 1.5 and 2.2 (Table 1 ).

\section{Swimming behavior}

Hawaiian spotted boxfish used various combinations of pectoral, anal and dorsal fins to locomote over all but the highest swimming speeds. The pectoral fins began the forward stroke (abduction) with the anterior leading edge peeling away from the body ventrally and rostrally, the trailing rays following. At the most ventral position, the leading edge folded sharply upwards, initiating fin adduction (Fig. 4). The anterior edge of the fin led the trailing edge, but any perceived undulation was probably the passive result of this progression. The pectoral fin bases of $O$. meleagris are inclined at nearly $-45^{\circ}$ with respect to the horizontal, a common orientation for tetraodontiform fishes. The anal and dorsal fins oscillated back and forth in a highly compressed 'figure-of-eight' normal to the body axis.

At low swimming speeds, up to approximately $1 T L \mathrm{~s}^{-1}$, boxfish swam using combinations of pectoral and anal fin motions only. The dorsal and caudal fins were typically furled but were occasionally used for single beats. Similar behavior was frequently observed in fish hovering in the holding tanks and in their natural habitat. At speeds of $1-5 T L \mathrm{~s}^{-1}$, dorsal and anal fin-beat frequencies (Fig. 5) and amplitudes (Fig. 6) increased with speed up to $2.5-3 T L \mathrm{~s}^{-1}$, above which the finbeat amplitudes plateaued. At speeds above $5 T L \mathrm{~s}^{-1}$, fish were unable to maintain position in the flow using the median and paired fins alone and alternated the use of these fins with bursts of caudal-fin propulsion. At such times, the caudal fin executed 3-4 rapid beats, while the other fins were maximally adducted. The caudal fin was then furled as the pectoral and anal/dorsal fin complexes recommenced their movements. The frequency of caudal-fin bursts increased from $0.5 \mathrm{~Hz}$ at $5 T L \mathrm{~s}^{-1}$ to $1.5 \mathrm{~Hz}$ at $5.7 T L \mathrm{~s}^{-1}$. We observed boxfish swimming at surprisingly high speeds, occasionally in excess of $6 T L \mathrm{~s}^{-1}$. At these higher speeds, the burst-and-coast

Table 2. Dissection data for gross body composition of Ostracion meleagris camurum by wet mass

\begin{tabular}{|c|c|c|c|c|c|c|c|c|c|c|}
\hline \multirow{3}{*}{$\begin{array}{l}\text { Fish } \\
\text { number }\end{array}$} & \multirow{3}{*}{$\begin{array}{l}\text { Wet mass } \\
(\mathrm{g})\end{array}$} & \multicolumn{9}{|c|}{ Body component } \\
\hline & & \multicolumn{2}{|c|}{ Carapace } & \multicolumn{2}{|c|}{ Viscera/skeleton } & \multicolumn{2}{|c|}{ White muscle } & \multicolumn{2}{|c|}{ Red muscle } & \multirow{2}{*}{$\begin{array}{l}\text { Total } \\
(\%)\end{array}$} \\
\hline & & $(\mathrm{g})$ & $(\%)$ & $(\mathrm{g})$ & $(\%)$ & (g) & $(\%)$ & $(\mathrm{g})$ & $(\%)$ & \\
\hline 2 & 77.2 & 15.97 & 20.7 & 25.81 & 33.4 & 22.23 & 28.8 & 5.99 & 7.8 & 90.7 \\
\hline 3 & 30.5 & 7.19 & 23.6 & 11.68 & 38.3 & 7.07 & 23.2 & 1.80 & 5.9 & 91.0 \\
\hline 6 & 46.3 & 9.42 & 20.4 & 14.26 & 30.8 & 14.50 & 31.3 & 4.36 & 9.4 & 91.9 \\
\hline Mean & 50.7 & 10.81 & 21.9 & 18.43 & 37.2 & 13.81 & 26.4 & 3.47 & 6.6 & 91.9 \\
\hline S.E.M. & 8.1 & 1.59 & 0.9 & 2.83 & 2.1 & 2.98 & 1.7 & 0.84 & 0.8 & 0.5 \\
\hline
\end{tabular}

Individual component and total component contributions are also given as a percentage of whole-body wet mass. 


\section{J. R. HOVE AND OTHERS}

Fig. 4. Pectoral fin orientation throughout a single fin-beat cycle for Ostracion meleagris camurum swimming at $1.5 T L \mathrm{~s}^{-1}$, where $T L$ is total body length. The images were obtained from direct tracings of video images. The underside of the fin is shaded for contrast.

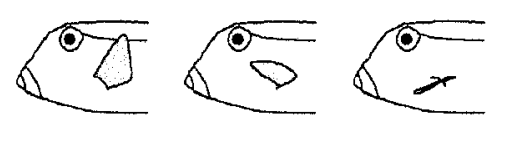

Fin abduction

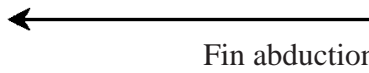

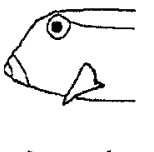
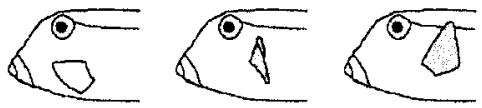

swimming was essentially a 'kick-and-glide' behavior seen in several BCF swimmers (Jayne and Lauder, 1994; Jayne and Lauder, 1995). Contrary to previous anecdotal descriptions, sculling movements of the caudal fin at submaximal swimming speeds were not observed at any time. Fine-scale movements of the caudal fin were measured at these lower speeds, but whether this represented active compensation for recoil produced by the orthogonal fin pairs or whether the movements were merely passive is not known.
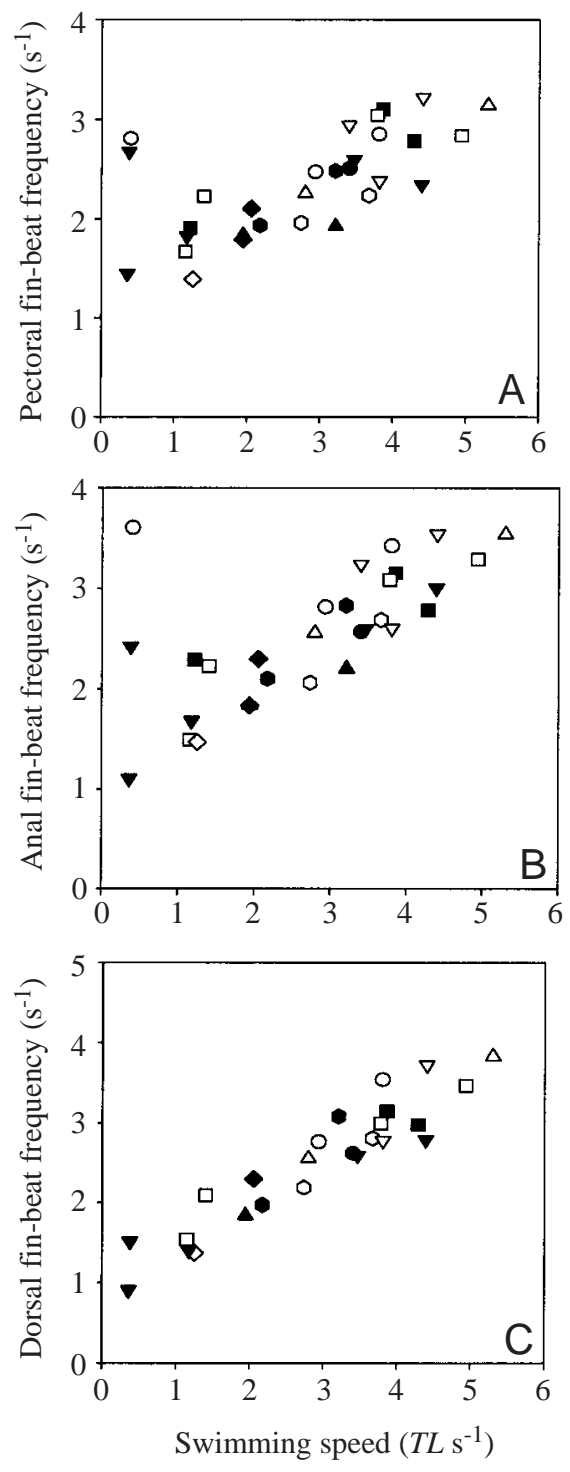

Fig. 5. Relative fin-beat frequencies of five Hawaiian boxfish Ostracion meleagris camurum over a range of relative swimming speeds. Each symbol represents the performance of a single fish at a given speed. $T L$, total body length.

\section{Median- and paired-fin kinematics}

Anal and pectoral fin-beat frequencies were more variable than dorsal fin-beat frequencies, especially at low $\left(<2 T L \mathrm{~s}^{-1}\right)$ swimming speeds. At speeds above $1 T L \mathrm{~s}^{-1}$, up to the onset of burst-and-coast caudal-fin propulsion, the beat frequencies of
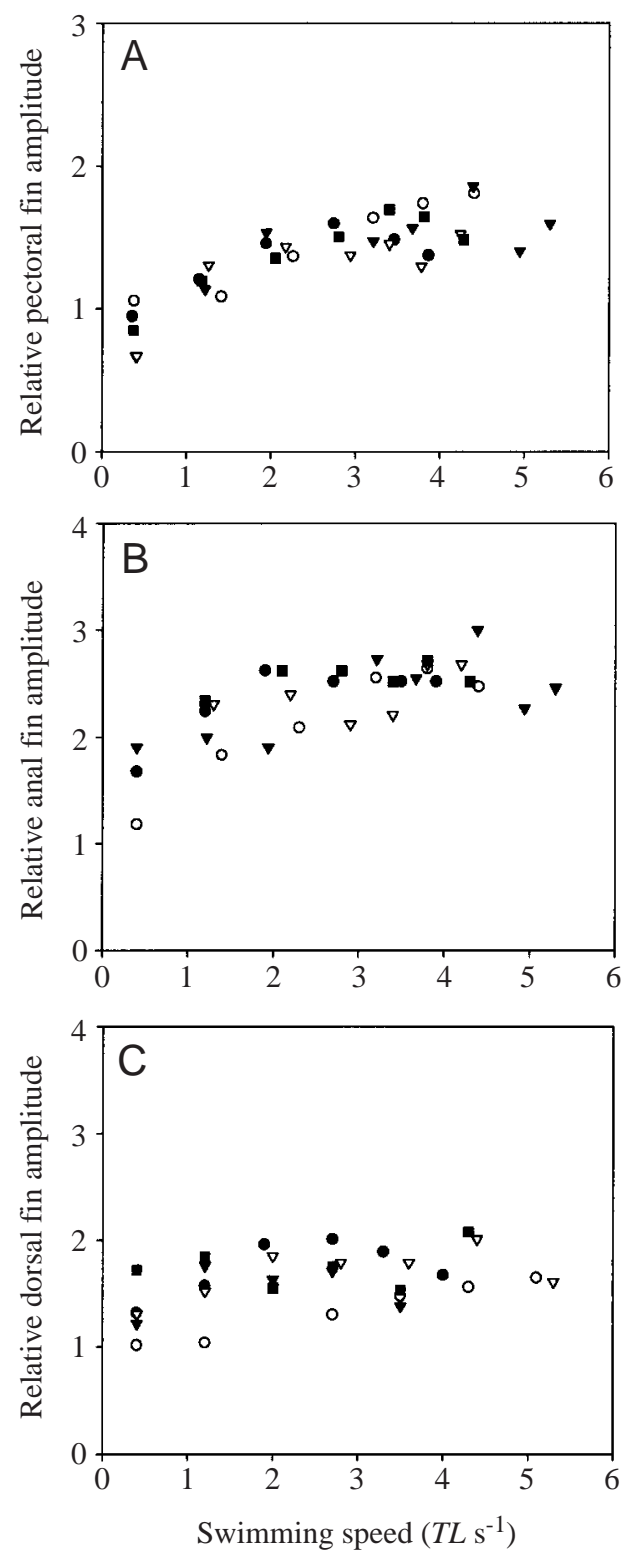

Fig. 6. Relative fin-beat amplitudes of five Hawaiian boxfish Ostracion meleagris camurum over a range of relative swimming speeds. Each symbol represents the performance of a single fish at a given speed. Body size effects have been removed by reporting relative amplitudes (fin tip displacement/fin span). $T L$, total body length. 
all fins were proportional to swimming speed (Fig. 5A-C). Dorsal fin-beat frequencies increased at the same rate (slope $0.54, r^{2}=0.82$ ) as anal fin-beat frequency (slope 0.46, $r^{2}=0.73$; no significant difference in slopes). Pectoral fin-beat frequencies increased significantly less rapidly (slope 0.35 , $r^{2}=0.65$ ). No pause (i.e. refractory period) was observed at the point of direction change during the fin-beat cycles of any of the median and paired fins.

The relative fin-beat amplitudes of the pectoral and anal fins increased monotonically from values of approximately 1.0 and 1.5 , respectively, towards asymptotes of the order of 2 and 2.5 between 3 and $6 \mathrm{TL} \mathrm{s}^{-1}$ (Fig. 6A,B). In contrast, dorsal fin relative amplitude averaged 1.5-2, irrespective of swimming speed (Fig. 6C). Anal fin values exceed the expected asymptote of 2 as a result of the choice of the location of span measurement. The fin spans were measured from the distal end of the fin base to the fin tip at the second fin ray (near the leading edge). As a result, they do not include the fin bases, which are flexible and oscillate with the fins. Because the anal fins have longer (and perhaps more flexible) fin bases than do the dorsal fins, measurements of amplitude swept out by the fin tip exceeded twice the span as measured.

The dorsal and anal fins moved in compressed figures of eight normal to the incident flow with equal left and right motions. Projecting the traces of the pectoral fin tips throughout a single fin-beat cycle on a sagittal plane (Fig. 7) reveals that the trajectories are best described as posteriorly inclined figures of eight. The pectoral fin tip moved counterclockwise through the smaller 'dorsal loop' and clockwise through the larger 'ventral loop' at low swimming speeds $\left(1.3 T L \mathrm{~s}^{-1}\right)$, but loop size asymmetry decreased with increasing forward swimming speed until nearly $2.9 \mathrm{TL} \mathrm{s}^{-1}$. Pectoral fin-beat planes, defined as the angle subtended by a line bisecting the figures of eight (drawn by eye) and the horizontal, increased from approximately 34 to $50^{\circ}$ between 1.3 and $4.5 \mathrm{TL} \mathrm{s}^{-1}$. At lower swimming speeds, the fin-beat plane is more orthogonal to the pectoral fin base, but at higher speeds (e.g. $4.5 \mathrm{TL} \mathrm{s}^{-1}$ ) the beat plane inclines to $50^{\circ}$.

Pectoral fin abduction took significantly longer to complete than the adduction phase of the fin-beat cycle at all speeds (Fig. 8 ; $t$-test, $P<0.005)$. Pectoral fin adduction made up 32-46\% of the overall stroke period. During the adduction phase, the anterior (dorsal) rays led the posterior rays such that the angle of the fin blade moved forward at a small angle to the incident flow.

\section{Coordination of fin movements}

The pectoral fins of the boxfish typically beat together at low speeds $\left(<2.5 T L \mathrm{~s}^{-1}\right.$ ), with $\mathrm{d} t / \tau$ values less than 0.1 (Figs 9A,B, 10). As swimming speed increases to moderate $\left(3.8 \mathrm{TL} \mathrm{s}^{-1}\right)$ MPF levels, the pectoral fins become less synchronized $(\mathrm{d} t / \tau=0.4)$, and at high MPF speed $\left(4.5 T L \mathrm{~s}^{-1}\right)$ they beat in a highly asynchronous fashion. In contrast, with the exception of hovering and swimming speeds less than $1 T L \mathrm{~s}^{-1}$, the dorsal and anal fins beat in phase at all times. The coordination between the pectoral fins and the dorsal/anal fin complex was statistically insignificant, although the complex appeared to
Fig. 7. Tracings of pectoral fin tip trajectories over four complete fin-beat cycles at each of four relative swimming speeds. $T L$, total body length.
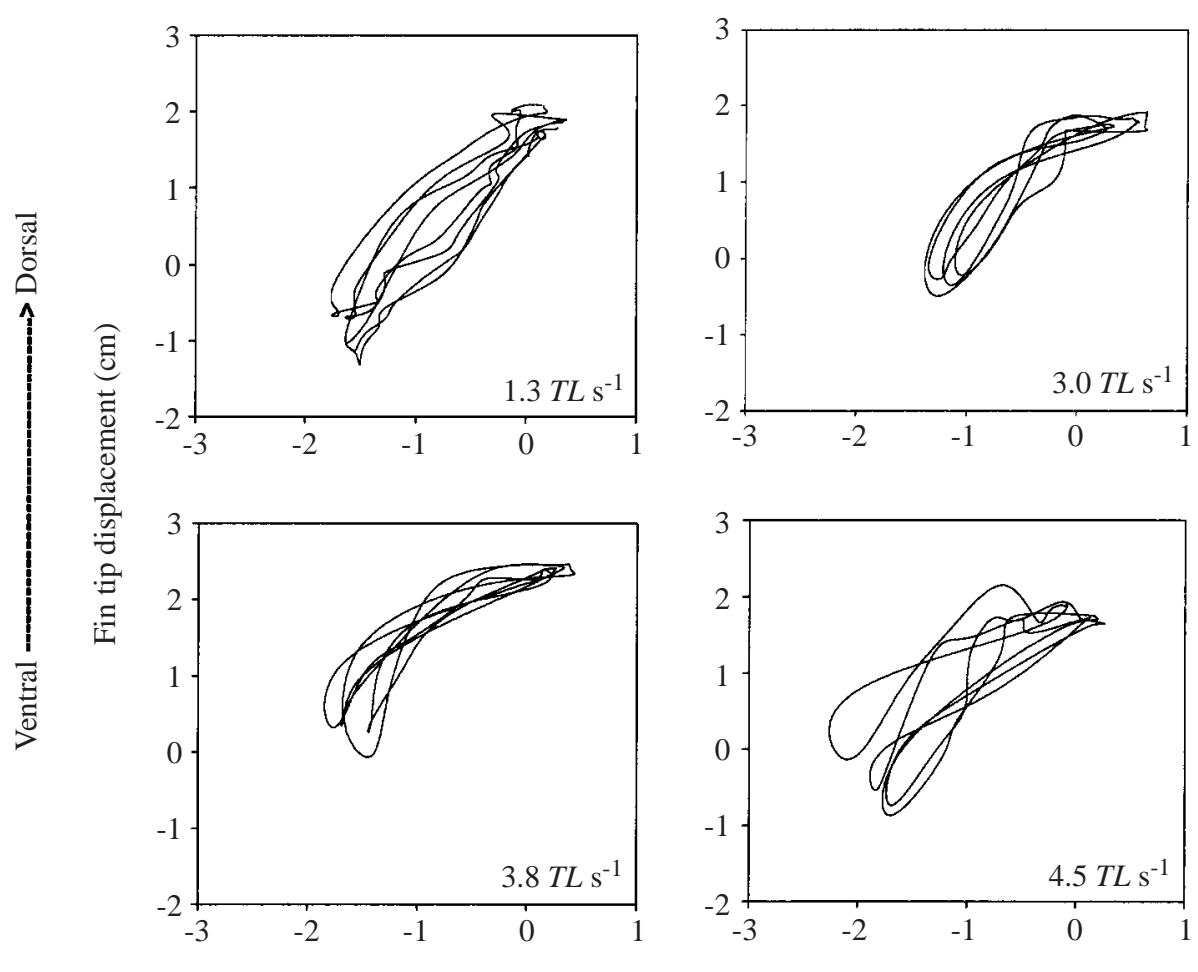

Fin tip displacement $(\mathrm{cm})$

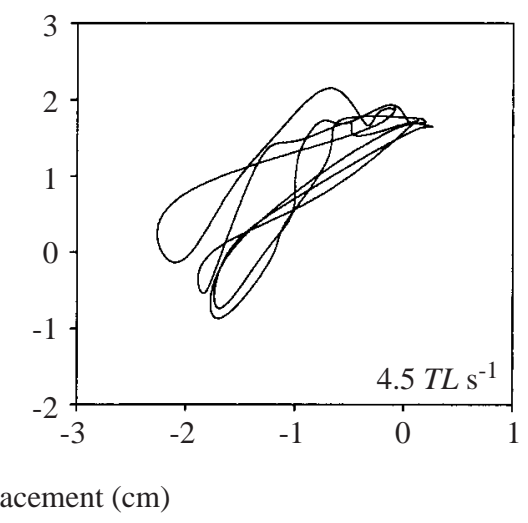

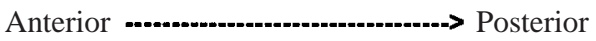




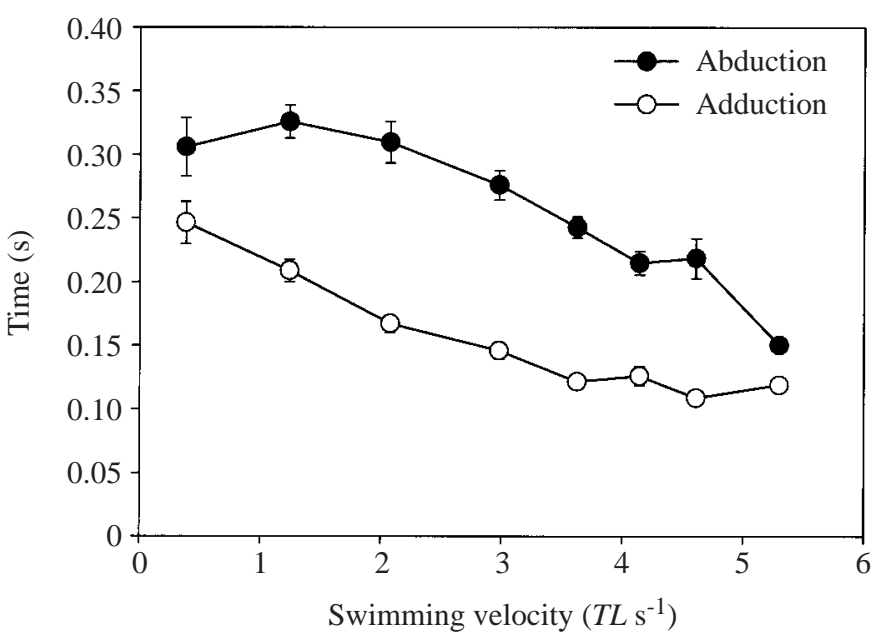

Fig. 8. Mean periodicity of pectoral fin adduction and abduction of Ostracion meleagris camurum swimming over a range of induced relative speeds. Each point represents an average of four fin-beat cycles. Values are means \pm S.E.M. $T L$, total body length.

become increasingly out of phase with increasing speed (Figs 9C,D, 10).

\section{Median- and paired-fin swimming trajectories}

Observations of boxfishes swimming both in nature and in the flume indicate that they move in dynamically wellcontrolled rectilinear trajectories. With the exception of pitch (regression, $y=0.004 x+0.062, r^{2}=0.14$ ) and yaw (regression, $y=0.013 x+0.034, \quad r^{2}=0.53$ ) (Fig. 11A,B), measured recoil motions were so small as to be virtually undetectable above noise levels. The magnitudes of both translational and rotational recoil motions of swimming boxfish were substantially smaller than those reported for most BCF swimmers (Table 3).

\section{Discussion \\ General}

Classical descriptions beginning with Breder (Breder, 1926) state that boxfishes locomote by sculling themselves through the water using only their tails. We have shown that this description is incomplete. Boxfishes actually use coordinated, synchronized movements of five fins, the two pectoral fins and the dorsal, anal and caudal fins, to produce a wide repertoire of controlled swimming movements. Using these fins, boxfishes attain much higher swimming speeds $\left(>6 T \mathrm{~L} \mathrm{~s}^{-1}\right)$ than expected on the basis of the performance of two tetraodontiform swimmers, Arothron meleagris and $A$. nigropunctatus (maximum swimming speed $U_{\max } \approx 4 T L \mathrm{~s}^{-1}$ ) (Gordon et al., 1996). In addition, they swim with minimal recoil. The stereotype of these animals as slow and clumsy is therefore untrue.
Fig. 9. Fin-beat synchrony plots for the left (red, filled circles) and right (green, filled circles) pectoral fins and the dorsal/anal fin complex (blue, open circles) of Ostracion meleagris camurum over four swimming speeds. The solid line $y=0$ represents the 'zero crossings' (see text and Fig. 2). $T L$, total body length.
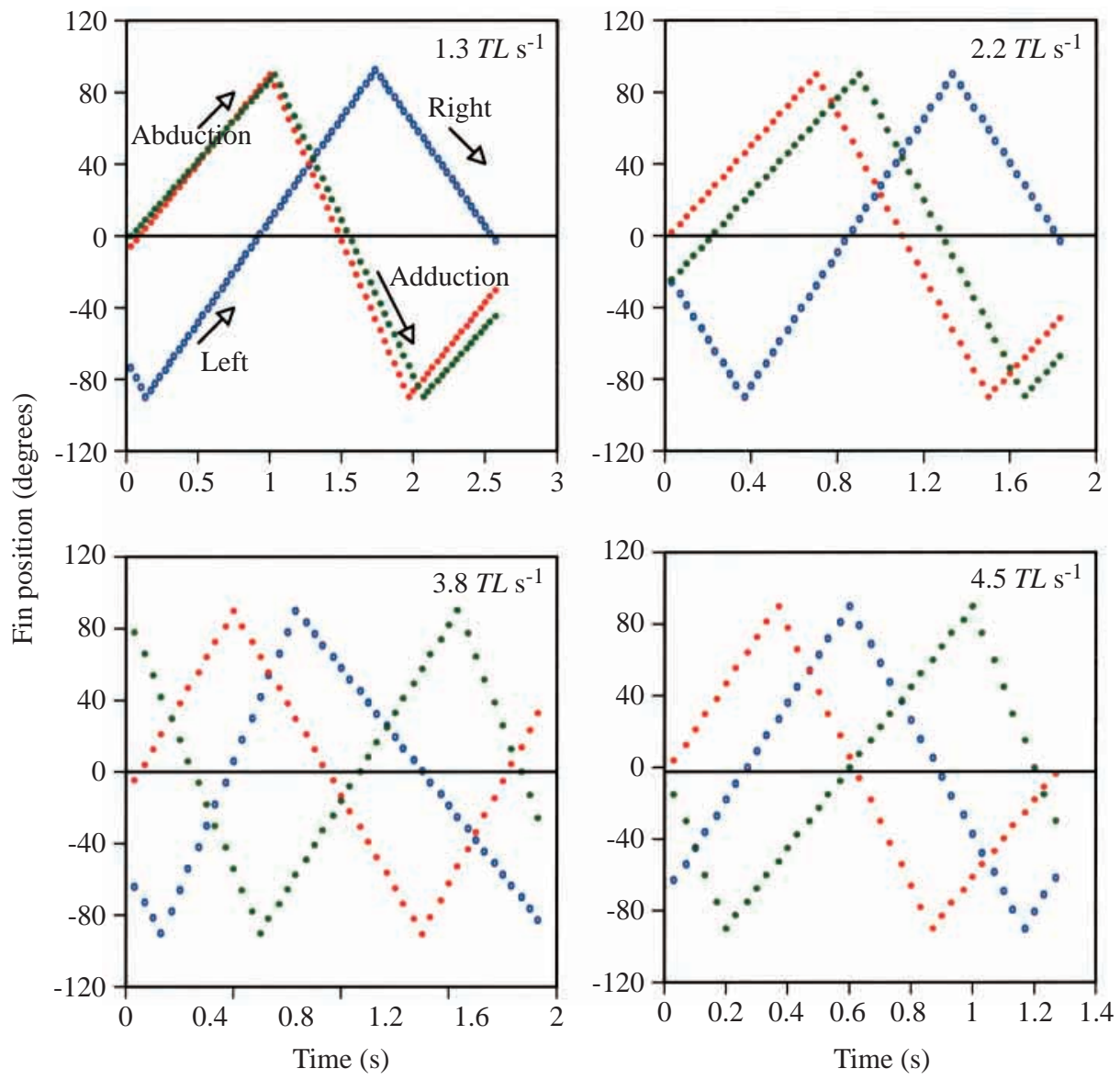


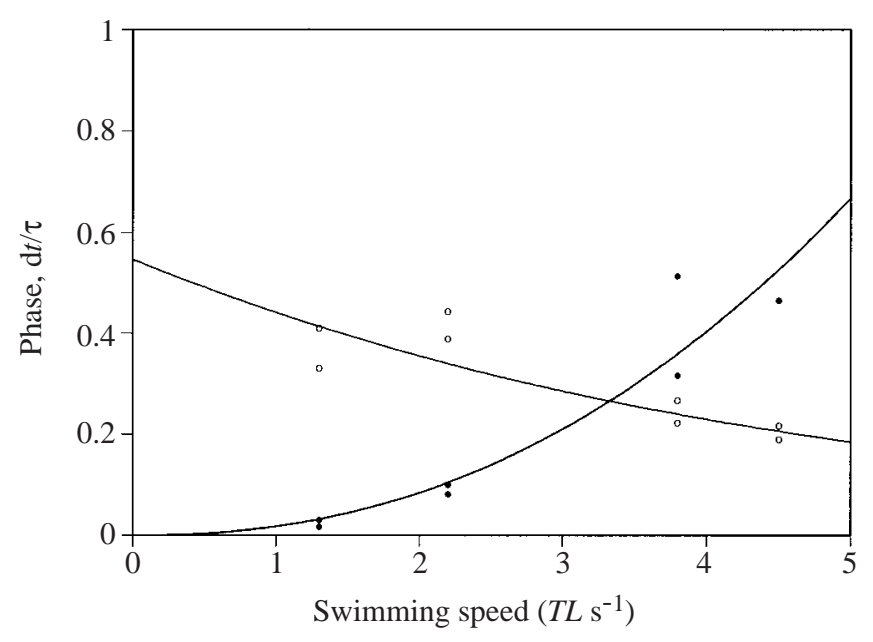

Fig. 10. The phase relationship between the two pectoral fins (filled circles) and between the pectoral fin complex and the anal/dorsal fin (open circles) complex as a function of swimming speed. The observed swimming gaits for Ostracion meleagris camurum are overlaid for gait transition analysis. $T L$, total body length; $t$, time; $\tau$, the time between digitized points within a fin beat.

\section{Kinematics of ostraciiform propulsion}

To increase thrust and swim faster, fish vary the kinematics of their propulsors within a gait, most commonly fin-beat frequency and amplitude. The beat frequencies of both the median and paired fins of boxfish increased linearly with swimming speed. Amplitude increased monotonically with speed up to nearly $3 T L \mathrm{~s}^{-1}$, above which it plateaued and further thrust was provided by increasing fin-beat frequency (Figs 5, 6). The product of frequency and amplitude decreases at higher speeds, but so does stability. The asymptotic relationship between fin-beat amplitude and swimming speed observed in the spotted boxfish is also seen in BCF swimmers (Bainbridge, 1958; Webb, 1988b). Amongst MPF swimmers studied, this relationship is exhibited by the labriform swimmers Cymatogaster aggregata (Webb, 1973) and Embiotoca lateralis (Drucker and Jensen, 1996a; Drucker and Jensen, 1997) but not by Gomphosus varius (Walker and Westneat, 1997).

As seen in other species (Geerlink, 1983; Archer and Johnston, 1989; Westneat, 1996), the pectoral fins of the boxfish have a temporally asymmetric beat cycle, with fin abduction being significantly slower than the adduction phase. This may indicate that the adducting fin is serving as the power stroke of the fin-beat cycle. A difference in stroke timing could be due to differential contributions to thrust versus weight support, as has been shown in birds (Weis-Fogh, 1974), but this seems unlikely in near-neutrally buoyant boxfishes. Nevertheless, feathering the pectoral fins during the lowerspeed adduction phase should minimize resistance. Such propulsor movement patterns are frequently seen in drag-based systems (Blake, 1981).

As has been demonstrated in a lift-based labriform system (G. varius; Walker and Westneat, 1997), the spotted boxfish
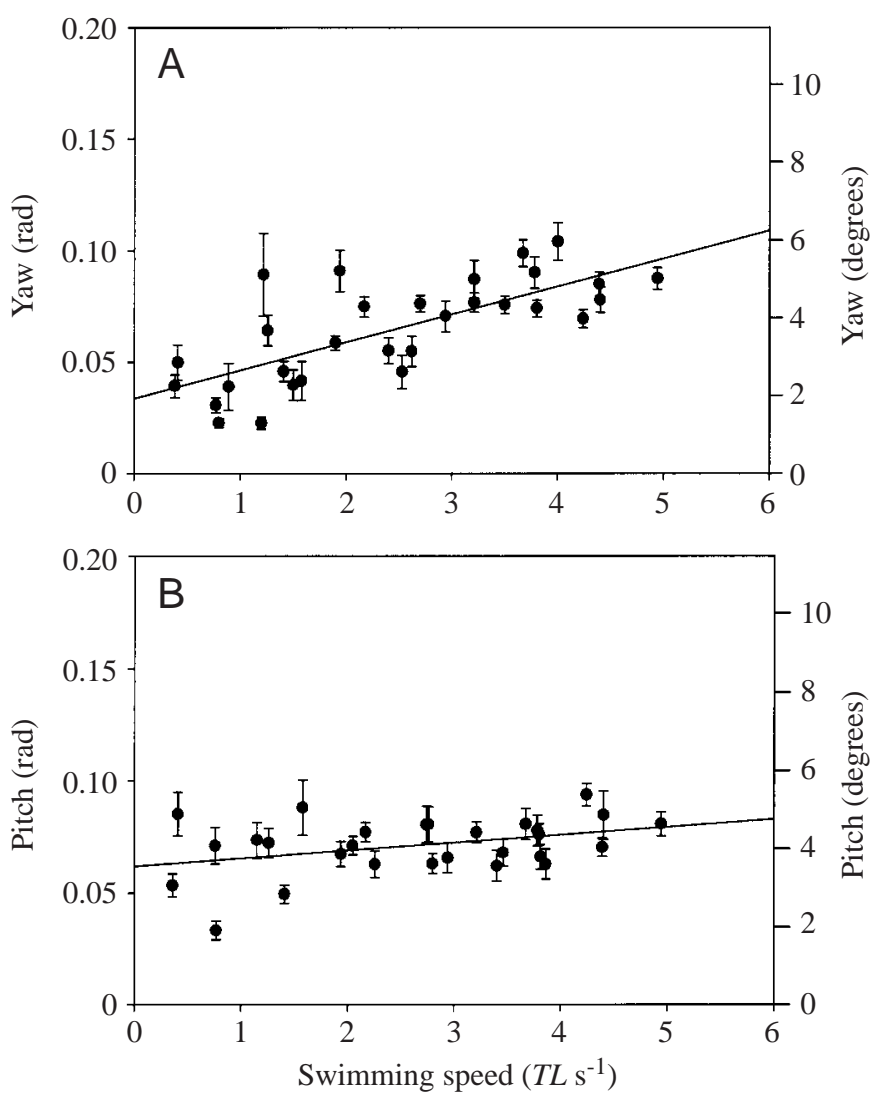

Fig. 11. Magnitudes of (A) yaw and (B) pitch angles in Hawaiian spotted boxfish (Ostracion meleagris camurum) over a range of relative swimming speeds. Values are means \pm S.E.M., $N=3$. $T L$, total body length.

exhibited no detectable delay (refractory period) between consecutive pectoral fin-beat cycles. Although Archer and Johnston (Archer and Johnston, 1989) showed that the negatively buoyant Notothenia neglecta had refractory periods at maximum abduction, most studies of MPF swimmers (Webb, 1973; Gibb et al., 1994; Drucker and Jensen, 1996a; Drucker and Jensen, 1997) have demonstrated a significant refractory period at the end of the adduction phase.

The pectoral fin bases of fishes using lift-based propulsion (e.g. wrasses and other aquatic 'fliers') are nearly horizontal (inclined $0^{\circ}$ posteriorly), whereas fishes using true drag-based propulsion (e.g. angelfish and other 'rowers') have more vertically oriented bases (near $90^{\circ}$ posterior inclination). Boxfish fin bases, like those of tetraodontiform fishes, are located midway between these extremes, suggesting a combination of lift- and drag-based kinematics. The deviation from a beat plane normal to the flow during adduction, and parallel to the flow in the abduction phase, could result in the creation of lift throughout the beat. This expectation is reasonable because lift-based propulsion is more efficient at higher speeds than drag-based rowing. However, using a more drag-based kinematic pattern at lower swimming speeds should allow boxfishes still to swim steadily in those lower speeds as they support their weight in the water. 


\section{J. R. HOVE AND OTHERS}

Table 3. Relative yaw of various body and caudal-fin swimmers and of the spotted boxfish Ostracion meleagris camurum over a range of body sizes and swimming speeds

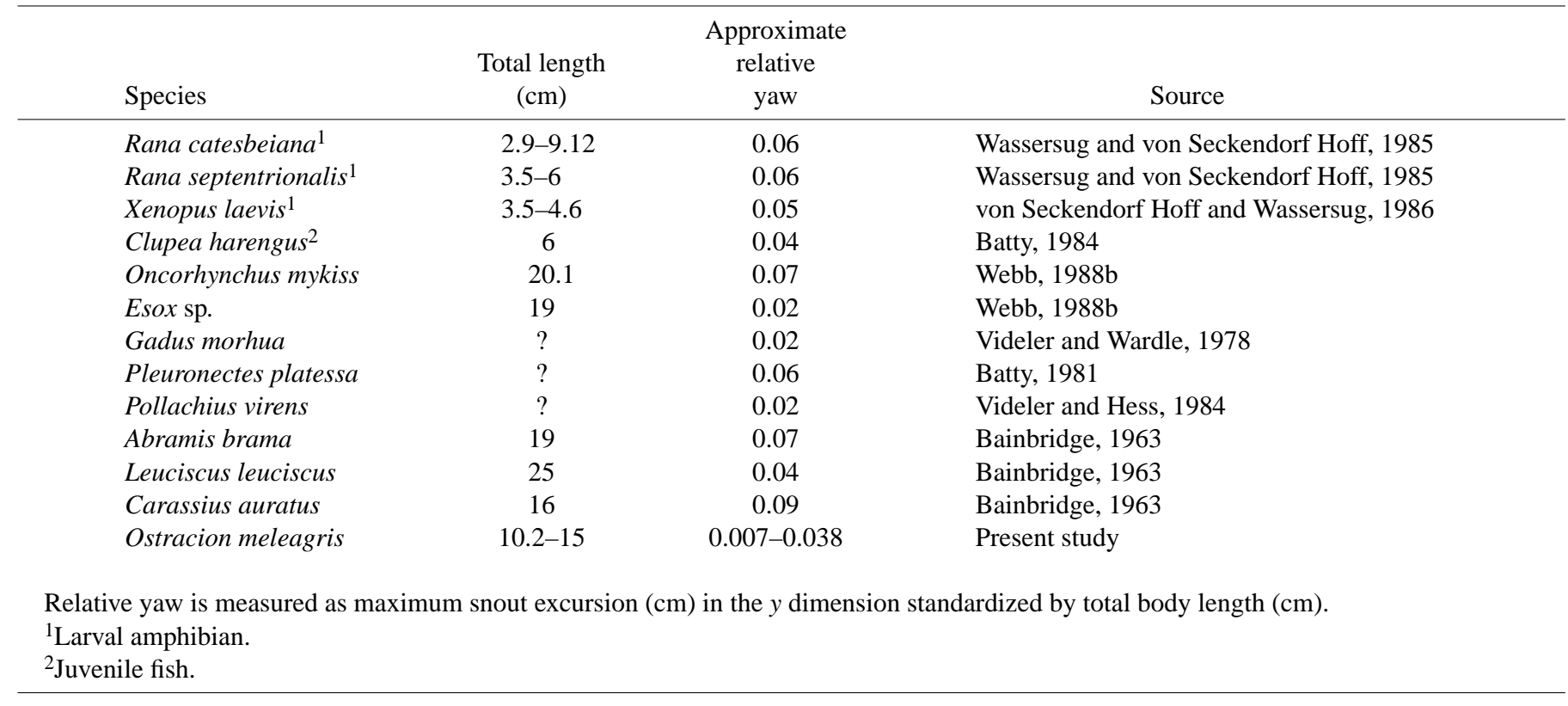

The fact that boxfishes have four low-aspect-ratio (Table 1) median and paired fins of nearly identical area comparably positioned around the circumference of a body of symmetrical cross section undoubtedly has implications for dynamic stability. The kinematics of the pectoral propulsors in $O . m$. camurum described above suggests that these fins may utilize lift- (circulation) or drag- (reaction) based mechanics or perhaps some combination of both. Jayne and Lauder (Jayne and Lauder, 1996) reached the same conclusion for a variety of fishes using labriform swimming modes. Another source of propulsive force may be found in unsteady mechanisms. Fishes swimming at Reynolds numbers $(R e)$ from 30 to approximately $10^{4}$ theoretically derive a substantial proportion of the forward thrust component from pressure drag and the acceleration reaction (Webb, 1988a). The boxfishes in this study experienced $R e$ values up to approximately $6 \times 10^{3}$. The reduced frequency parameter $(\sigma)$ is a relative estimate of the importance of unsteady mechanisms in thrust production (Daniel, 1984). Our values of $\sigma$ for $O$. m. camurum were approximately 0.98 , above the generally accepted value of $\sigma=0.4$, and indicative that the acceleration reaction is a major factor in force production. J. R. Hove, M. S. Gordon, L. M. O'Bryan, P. W. Webb and D. Weihs (in preparation) give a more detailed discussion of the hydromechanical aspects of boxfish swimming. At this juncture, we will point out that the important morphological features of the fins and their kinematics suggest very complex hydrodynamic interactions between the propulsors, the body and the surrounding water.

\section{Ostraciiform swimming gaits}

Separating the entire locomotor performance range into distinct gaits is a method of minimizing energy expenditure at a given speed and thus allowing for a wider range of performance. Each gait is typified by, among other things, a specific kinematic pattern (Alexander, 1989; Webb, 1994). While initially used to describe pedestrian locomotion, gaits are also applicable to both flying and swimming performance enhancement.

Living in an aqueous environment and possessing a welldeveloped swimbladder makes most fishes nearly neutrally buoyant. With gravitational effects being negligible, fishes are not only free to vary the kinematic patterns of their propulsors, but they may also actually recruit them differentially as needed. For the purposes of this discussion, we here use the definition of Alexander (Alexander, 1989) of a gait: 'a pattern of locomotion characteristic of a limited range of speeds described by quantities of which one or more change discontinuously at transitions to other gaits'. On the basis of this definition and the fin kinematics described above, three distinct swimming gaits used by $O . \mathrm{m}$. camurum were observed. These are: (i) pectoral/anal-fin-dominant (PA), $0-1 T L \mathrm{~s}^{-1}$; (ii) anal/dorsal-fin-dominant (AD), $1-5 T L \mathrm{~s}^{-1}$; and (iii) caudal burst-and-coast (CBC), $5+T L \mathrm{~s}^{-1}$.

These gaits are used for routine translocation. At least two other gaits (hovering and 'kick-and-glide') are used by boxfishes but, because these swimming gaits are beyond the scope of this study (i.e. they are the extrema bounding MPF swimming), they are not addressed in the following descriptions.

\section{Pectoral/anal-fin-dominant (PA) swimming}

At swimming speeds between 0 and $1 T L \mathrm{~s}^{-1}$, boxfishes are generally either inspecting a stationary food item or moving along a variable trajectory characterized by directional changes. The motions of the pectoral and anal fins appear to be the primary thrust producers on the basis of relative fin-beat activity. 
The pectoral fins move either synchronously or asynchronously, with no apparent pattern. This is reasonable because their swimming trajectories are often highly variable (i.e. they execute a number of turns) at these speeds. The anal fin moves at low frequency, sweeping out paths of relatively uniform amplitude. Both the anal and pectoral fin-beat frequencies were highly variable at these low swimming speeds, probably associated with supporting the weight of the fish in water (Webb, 1993) and the numerous turns executed. The dorsal fins are rarely used during this gait, and the caudal fin remains furled except for the occasional flick to help change direction.

\section{Anal/dorsal-fin-dominant ( $A D)$ swimming}

AD swimming covers the majority $\left(1-5 T L \mathrm{~s}^{-1}\right)$ of the boxfish swimming speed range studied. It is characterized, initially, by the recruitment of the dorsal fin, which beats in phase with the anal fin. In this gait, propulsion is produced by oscillations of both the dorsal/anal fin and the pectoral fin complexes. The frequencies and amplitudes of the pectoral and dorsal/anal fin complexes increase linearly with speed, and pectoral fin amplitude plateaus at speeds greater than $3 T L \mathrm{~s}^{-1}$. Furthermore, the rate of increase in beat frequency is greater for the dorsal/anal fin complex than for the pectoral fins, suggesting that these become the major propulsors at higher speed. At these higher speeds, the pectoral fins begin to work asymmetrically. Since the dorsal and anal fins beat synchronously, this will smooth the lateral forces produced by the motions of the pectoral fins and perhaps balance increasing fluid in the side forces of the dorsal/anal fin complex. The caudal fin 'flutters', but whether these are actively generated ruddering movements or just passive 'flagging' from the increasing stroke power of the anal/dorsal fin complex is unclear.

\section{Caudal burst-and-coast (CBC) swimming}

At the highest rectilinear speeds attained by boxfishes $\left(>5 T L \mathrm{~s}^{-1}\right)$, the caudal fin is used in a burst-and-coast mode. During these bouts, the pectoral fins are adducted and the dorsal/anal fin complex is aligned with the body axis, both undoubtedly to reduce drag. Some captured sequences of very high speed swimming indicated that the boxfish executed 'kick-and-glide'-like motions (Jayne and Lauder, 1994; Jayne and Lauder, 1995): they bent the peduncular region to a maximal lateral orientation and then executed a single hard beat that had the effect of accelerating the fish forward with considerable force. Only during these sequences was significant yawing recoil visible.

\section{Fin coordination and recoil analysis}

BCF swimming generates large side forces that cause the anterior parts of the body to recoil (yaw and/or sideslip). This has traditionally been thought to be associated with substantial loss of energy (Lighthill, 1971; Webb, 1975), although recent experiments with flapping foils and computational fluid dynamics (CFD) suggest that some BCF swimmers may use these lateral excursions to generate body flows that modify the caudal fin flow positively (Triantafyllou et al., 2000). The use of multiple propulsors substantially reduces such recoil in MPF swimmers (Gordon et al., 1996). Measurements in three dimensions of the trajectories of the centers of mass show that the rigid-bodied, multi-propulsor boxfish do in fact recoil during forward swimming. However, these recoil motions are small compared with the yawing seen in BCF swimmers (Table 3 ). Normalizing the amplitude of recoil motions (in this case yaw) to total body length, the snout of BCF swimmers sweeps relative amplitudes ranging from $2 \%$ (Videler and Wardle, 1978; Videler and Hess, 1984; Webb, 1988a) to $9 \%$ (Bainbridge, 1963) over a limited low-end range of swimming speeds, compared with $0.7-3.8 \%$ for boxfish over a full range $\left(0.5-5 T L \mathrm{~s}^{-1}\right)$ of speeds (Fig. 11A). Batty (Batty, 1984) measured relative yaw at $4 \%$ for juvenile $(6 \mathrm{~cm} \mathrm{TL})$ Clupea harengus, and Fig. 4 in that work suggests that larval herring (BL 11 and $22 \mathrm{~mm}$ ) showed no yaw at all, a surprising result and contrary to observations of other BCF swimmers.

Few studies have reported values for other types of body recoil in swimming fishes. Accelerometry measurements made on swimming bluefish (Pomotamus saltatrix) and striped bass (Morone saxatilis), both subcarangiform BCF swimmers, demonstrate increasing surge and sideslip with increasing speed (DuBois et al., 1976; Freadman, 1981). Surge and heave are visible in MPF pectoral fin fliers (labriform mode) such as Coris formosa (Geerlink, 1983) and Gomphosus varius (Westneat, 1996; Walker and Westneat, 1997). The swimming kinematics of the striped surfperch (Embiotoca lateralis), another pectoral fin swimmer (embiotociform mode), have been described (Drucker and Jensen, 1996a; Drucker and Jensen, 1996b; Drucker and Jensen, 1997), and they also demonstrate significant heave, which increases at higher swimming speeds (E. Drucker, personal communication). Even Antarctic fish (Notothenia neglecta) that swim using an MPF labriform mode at low speeds and a BCF subcarangiform mode at elevated speeds demonstrate surging recoil (Archer and Johnston, 1989). No surge or heave was observed in the bluegill sunfish Lepomis macrochirus (Gibb et al., 1994), indicating either that it is an exceptionally stable swimmer or that the resolution of the methods was insufficient to isolate recoil motions from system noise. The boxfishes examined in the present study showed no significant surge, heave, roll or sideslip. Only low levels of yaw and pitch (Fig. 11A,B) were measurable. On the basis of these data, it appears that propulsion with multiple fins does indeed provide for smoother trajectories than BCF propulsion or single-complex MPF propulsion.

Having established that boxfishes locomote with a minimum of recoil motions, the next question to ask is how such effective dynamic control of swimming trajectory is accomplished. There are several ways. First, single propulsors, whether the caudal fin by itself (BCF swimmers) or paired pectoral fins working together (e.g. labriform or embiotociform swimmers), do not produce continuous thrust because they oscillate. This produces recoils in the planes of thrust production: yaw and surge with BCF propulsors (DuBois et al., 1976; DuBois and Ogilvy, 1978; Freadman, 1981) and heave with labriform flyers 
(Webb, 1973; Geerlink, 1983; Archer and Johnston, 1989; Drucker and Jensen, 1996a; Drucker and Jensen, 1996b; Drucker and Jensen, 1997; Walker and Westneat, 1997). As we have seen, when multiple propulsors are used, phase differences in their oscillations can smooth thrust production. In pufferfish, the pectoral fins are $180^{\circ}$ out of phase, so that one fin executes its power phase during adduction of the other. The dorsal and anal fins, apparently generating lift, beat at the same frequency and out of phase with the pectoral fins. These primarily lift-based median fins generate thrust during both left and right movements (Gordon et al., 1996).

The boxfish similarly uses a combination of at least partially lift-based dorsal and anal fins. In contrast to pufferfish, these fins beat at higher rates than the pectoral fins (Fig. 5). Therefore, for most of the time, the pectoral fins and the dorsal and anal fins will be somewhat out of phase. In addition, the pectoral fins become increasingly unsynchronized as speed increases. The net result is propulsion not only with no detectable surge but also with little recoil in other directions. Another way that fish may reduce recoil is to use multiple short waves within a single propulsor. This may occur in fishes swimming with long-based median fins such as the gymnotiform swimmers (Blake, 1980; Blake, 1983). Clearly, this does not apply to boxfish locomotion.

We thank the staff at the Oceanic Institute, Waimanalo, Hawaii, Kimberly Selkoe, Dean Lauritzen and Scott Matthews for their administrative and logistical support for this project. We also extend our gratitude to Mike Eng and Richard Klufas of the UCLA Life Sciences electrical and machine shops and Steven Grubweiser and Joe Becker of the UCLA engineering shop for fabrication and customization of the water tunnel and its many appurtenances. This work was made possible by funding from the Office of Naval Research (research grant numbers N100014-96-0607 and N00014-97-10619 to M.S.G.).

\section{References}

Alexander, R. McN. (1989). Optimization and gaits in the locomotion of vertebrates. Physiol. Rev. 69, 1199-1227.

Archer, S. D. and Johnston, I. A. (1989). Kinematics of labriform and subcarangiform swimming in the antarctic fish Notothenia neglecta. J. Exp. Biol. 143, 195-210.

Arnold, G. P. and Weihs, D. (1978). The hydrodynamics of rheotaxis in the plaice (Pleuronectes platessa L.). J. Exp. Biol. 75, 147-169.

Bainbridge, R. (1958). The speed of swimming of fish as related to size and to the frequency and amplitude of the tail beat. J. Exp. Biol. 35, 109-133.

Bainbridge, R. (1963). Caudal fin and body movement in the propulsion of some fish. J. Exp. Biol. 40, 23-56.

Baroni, M. (1994). Elliptic Fourier approximation with application to left ventricular contour analysis. Comp. Meth. Progr. Biomed. 42, 33-38.

Batty, R. S. (1981). Locomotion of plaice larvae. Symp. Zool. Soc. Lond. 48, 53-69.
Batty, R. S. (1984). Development of swimming movements and musculature of larval herring (Clupea harengus). J. Exp. Biol. 110, 217-229.

Blake, R. W. (1977). On ostraciiform locomotion. J. Mar. Biol. Ass. U.K. 57, 1047-1055.

Blake, R. W. (1980). Undulatory median fin propulsion of two teleosts with different modes of life. Can. J. Zool. 58, 2116-2119.

Blake, R. W. (1981). Mechanics of drag-based mechanisms of propulsion in aquatic vertebrates. Symp. Zool. Soc. Lond. 48, 29-52.

Blake, R. W. (1983). Swimming in the electric eels and knifefishes. Can. J. Zool. 61, 1432-1441.

Breder, C. M. (1926). The locomotion of fishes. Zoologica IV, 159-297.

Daniel, T. L. (1984). Unsteady aspects of aquatic locomotion. Am. Zool. 24, 121-134.

Domenici, P. and Blake, R. W. (1991). The kinematics and performance of the escape response in the angelfish (Pterophyllum eimekei). J. Exp. Biol. 156, 187-205.

Drucker, E. G. and Jensen, J. S. (1996a). Pectoral fin locomotion in the striped surfperch. I. Kinematic effects of swimming speed and body size. J. Exp. Biol. 199, 2235-2242.

Drucker, E. G. and Jensen, J. S. (1996b). Pectoral fin locomotion in the striped surfperch. II. Scaling swimming kinematics and performance at a gait transition. J. Exp. Biol. 199, 2243-2252.

Drucker, E. G. and Jensen, J. S. (1997). Kinematic and electromyographic analysis of steady pectoral fin swimming in the surfperches. J. Exp. Biol. 200, 1709-1723.

DuBois, A. B., Cavagna, G. A. and Fox, R. S. (1976). Locomotion of bluefish. J. Exp. Zool. 195, 223-236.

DuBois, A. B. and Ogilvy, C. S. (1978). Forces on the tail surface of swimming fish: thrust, drag and acceleration in bluefish (Pomatomus saltatrix). J. Exp. Biol. 77, 225-241.

Freadman, M. A. (1981). Swimming energetics of striped bass (Morone saxatilis) and bluefish (Pomatomus saltatrix): hydrodynamic correlates of locomotion and gill ventilation. J. Exp. Biol. 90, 253-265.

Geerlink, P. J. (1983). Pectoral fin kinematics of Coris formosa (Teleostei, Labridae). Neth. J. Zool. 33, 515-531.

Gibb, A. C., Jayne, B. C. and Lauder, G. V. (1994). Kinematics of pectoral fin locomotion in the bluegill sunfish Lepomis macrochirus. J. Exp. Biol. 189, 133-161.

Gordon, M. S., Plaut, I. and Kim, D. (1996). How pufferfish (Teleostei: Tetraodontidae) swim. J. Fish Biol. 49, 319-328.

Haines, G. B. and Modde, T. (1996). Evaluation of marking techniques to estimate population size and first-year survival of Colorado squawfish. N. Am. J. Fish. Magmnt. 16, 905-912.

Jayne, B. C. and Lauder, G. V. (1994). How fish use slow and fast muscle fibers: Implications for models of vertebrate muscle recruitment. J. Comp. Physiol. A 175, 123-131.

Jayne, B. C. and Lauder, G. V. (1995). Are muscle fibers within fish myotomes activated synchronously? Patterns of recruitment within deep myomeric musculature during swimming in largemouth bass. J. Exp. Biol. 198, 805-815.

Jayne, B. C. and Lauder, G. V. (1996). Pectoral fin locomotion in fishes: testing drag-based models using three-dimensional kinematics. Am. Zool. 36, 567-581.

Lighthill, M. J. (1971). Large-amplitude elongated-body theory of fish locomotion. Proc. R. Soc. Lond. B 179, 125-138. 
Randall, J. E. (1972). The Hawaiian trunkfishes of the genus Ostracion. Copeia 1972, 756-768.

Triantafyllou, M. S., Triantafyllou, G. S. and Yue, D. K. P. (2000). Hydrodynamics of fishlike swimming. Annu. Rev. Fluid. Mech. 32, 33-53.

Videler, J. J. and Hess, F. (1984). Fast continuous swimming of two pelagic predators, saithe (Pollachius virens) and mackerel (Scomber scombrus): a kinematic analysis. J. Exp. Biol. 109, 209-228.

Videler, J. J. and Wardle, C. S. (1978). New kinematic data from high speed cine film recordings of swimming cod (Gadus morhua). Neth. J. Zool. 28, 465-484.

von Seckendorf Hoff, K. and Wassersug, R. J. (1986). The kinematics of swimming in the larvae of the clawed frog Xenopus laevis. J. Exp. Biol. 122, 1-12.

Walker, J. A. and Westneat, M. W. (1997). Labriform propulsion in fishes: kinematics of flapping aquatic flight in the bird wrasse Gomphosus varius (Labridae). J. Exp. Biol. 109, 209-228.

Wassersug, R. J. and von Seckendorf Hoff, K. (1985). The kinematics of swimming in anuran larvae. J. Exp. Biol. 119, 1-30.

Webb, P. W. (1973). Kinematics of pectoral fin propulsion in Cymatogaster aggregata. J. Exp. Biol. 59, 697-710.

Webb, P. W. (1975). Hydrodynamics and energetics of fish propulsion. Bull. Fish. Res. Bd Can. 190, 1-159.
Webb, P. W. (1988a). Simple physical principles and vertebrate aquatic locomotion. Am. Zool. 28, 709-725.

Webb, P. W. (1988b). 'Steady' swimming kinematics of tiger musky, an esociform accelerator, and rainbow trout, a generalist cruiser. $J$. Exp. Biol. 138, 51-69.

Webb, P. W. (1993). The effect of solid and porous channel walls on steady swimming of steelhead trout, Oncorhynchus mykiss. J. Exp. Biol. 178, 97-108.

Webb, P. W. (1994). The biology of fish swimming. In Mechanics and Physiology of Animal Swimming (ed. L. Maddock, Q. Bone and J. M. V. Rayner), pp. 45-62. New York: Cambridge University Press.

Webb, P. W. and Weihs, D. (1994). Hydrostatic stability of fish with swim bladders: not all fish are unstable. Can. J. Zool. 72, 1149-1154.

Weihs, D. (1993). Stability of aquatic animal locomotion. Contemp. Math. 141, 443-461.

Weis-Fogh, T. (1974). Flapping flight and power in birds and insects, conventional and novel mechanisms. In Swimming and Flying in Nature, vol. 2 (ed. T.Y.-T.Wu, C. J. Brokaw and C. Brennen), pp. 729-762. New York: Plenum Press.

Westneat, M. W. (1996). Functional morphology of aquatic flight in fishes: kinematics, electromyography and mechanical modeling of labriform locomotion. Am. Zool. 36, 582-598. 